\title{
Global HR Roles and Factors Influencing their Development: Evidence from Emerging Indian IT Services Multinationals
}

\begin{abstract}
The rapid growth of emerging markets' multinational companies (MNCs) is a recent phenomenon and as such their nature and structure of key management processes, functions and roles need further examination. While an abundance of low cost labor is often the starting point of competitive advantage for many of the emerging markets' MNCs, it is the optimum configuration of people, processes and technology that defines how they leverage their intangible resources. Based on case studies of four Indian IT services MNCs, involving 51 in-depth interviews of business and human resource (HR) leaders at the corporate and subsidiary levels, we identify five key HR roles, namely, strategic business partner, guardian of culture, builder of global workforce and capabilities, champion of processes, and facilitator of employee development. The analysis also highlights that the HR function in Indian IT services MNCs faces several challenges in consolidating the early gains of internationalization, such as lack of decentralized decision making, developing a global mindset, localization of workforce and developing a global leadership pipeline. Based on our exploratory findings, we propose a framework outlining the global HR roles pursued by emerging IT services MNCs, the factors influencing them, and the challenges facing their HR function for future research.
\end{abstract}

Keywords: Emerging Indian IT multinationals, international human resource management, Indian IT services industry, global human resource roles, determinants of human resource roles.

\section{Introduction}

A mixture of developments such as rapid globalization, the rise of emerging markets, technological developments, constant change and the emergence of intellectual capital as a key sustainable competitive advantage requires the HR function to be more strategic and global in its role, outlook and approach (Briscoe, Schuler \& Tarique, 2011; Chung, Bozkurt \& Sparrow, 2012; Khavul, Benson \& Dutta, 2010). In such a context, corporate HR plays a prominent role in the management of the global workforce in MNCs (Farndale, Scullion \& Sparrow, 2010a; Farndale, Paauwe, Morris et al., 2010b). Corporate HR is typically 
entrusted with assisting top management in the HR policy formulation for the entire global network of an MNC’s operations (Budhwar, 2012; Novicevic \& Harvey, 2001). There is a growing literature on the new forms of global HR roles with a specific reference to international operations (Evans, Pucik \& Björkman, 2011; Brandl \& Pohler, 2010; Sparrow, Harris \& Brewster, 2003) but unlike the traditional HR roles, there is a dearth of theoretical framework underpinning these new roles (Farndale et al., 2010b) and the contextual factors that influence the development of these roles, particularly in the emerging markets multinationals. Some of the main reasons surrounding this gap include the scarcity of reliable literature available on HRM in emerging markets' MNCs, the strong distinction in the internationalization strategies adopted by different emerging markets’ MNCs (e.g., Yaprak \& Karademir, 2010; Sethi, 2009), creating variations in their patterns of HRM systems overseas and the rapid pace of growth and change in many emerging markets; as a result, the management systems of such MNCs are still evolving and at present seems to be in a state of flux (see Ghemawat \& Hout, 2008). Also, the contextual pressures within which the emerging markets MNCs are evolving is different to established developed nations’ MNCs, which raises concerns regarding the suitability of the traditional HR global roles and the existing theoretical frameworks to study the HR roles in their global operations.

For example, in the context of emerging markets such as China and India, while there is a large pool of local labour, the workforce skills are still lacking by international standards (e.g., Budhwar \& Varma, 2011; Ready, Hill \& Conger, 2008). Further, it is still difficult to get expatriates to move to these economies, though this trend is now changing (GMAC, 2010). Based on such a premise, Ready et al. (2008) argue that in emerging markets, firms have no choice but to nurture local talent. Indeed, they also do it to survive and flourish in a rapidly increasing competitive environment created by the increasing presence of foreign firms in these economies. Supporting this view, initially Rosenzweig and Nohria (1994) and later Ryan and Gibbons (2011) believe that the changing global business trends are pulling MNCs more towards local responsiveness or isomorphism than the push for global integration of HR policies and practices. Considering the rapid economic growth of emerging markets, particularly from Asia, the focus on Asian management research has increased in recent years which is expected to extend and revise theories through the consideration of new contextual variables (Budhwar \& Debrah, 2009; Bruton \& Lau, 2008). It will also help to reveal the nature and pattern of management systems (including 
HRM) relevant for such contexts and also the logic underpinning the management of human resources in emerging markets MNCs (Chang, Mellahi \& Wilkinson, 2009; Schuler, Sparrow \& Budhwar, 2009).

However, due to the socio-cultural and institutional differences between nations we expect a variation in the nature of HR roles of emerging markets MNCs operating in both developed and developing markets. Supporting this view, Brewster, Wood and Brookes (2007) found that despite some evidence of common global HRM practices amongst MNCs, sufficient diversity in practices persist within a specific national context which could be explained by a duality perspective that reflects the persistent effects of institutional realities. While institutional theory has been widely used in the study of MNCs, Kostova, Roth and Dacin (2008) suggest that there is a danger of an 'implied institutional imperialism' in the Western-centric view of the role of MNCs and accordingly, they suggest broadening the theoretical lens by adopting a "blended institutional perspective, where the broad concepts of social embeddedness of organizations are intertwined with the ideas of agency, social construction, power and politics” (Kostava \& Dacin, 2009, p.1003).

The multiple typologies of HR roles largely originate from the United Kingdom or the United States (Farndale et al., 2010a); however, researchers stress that these roles are heavily influenced by the national, industry and organizational context (e.g., Farndale et al., 2010b). Given the business context of emerging economies is significantly different and in many ways unique to Western developed nations, and in order to highlight the contextual determinants of HR roles in emerging markets' MNCs, it is important to conduct research which can highlight the context-specific nature of HR. This paper makes a contribution in this regard by focusing on the emerging Indian multinationals in the IT services, which have gained a formidable global reputation for pioneering the global services delivery model, leveraging on their increasingly global workforce. It has been reported that the HR policies and practices in the Indian IT services industry are generally comparable to the best in the world (see Budhwar \& Varma, 2011). However, it is not clear what specific roles the corporate/global HR plays in this industry and what specific factors influence the development of these roles.

Against this background, our study aims to analyse the core roles played by the HR function of Indian IT services MNCs in their global operations (home and both in developed and developing nations context), 
highlight the key determinants of these roles and the challenges ahead. Such information should be useful to both researchers and practitioners to better understand the logic surrounding a less known but rapidly evolving phenomenon. To place these issues in context, we begin by providing an analysis of the literature on HR roles and contextual variables known to influence them, followed by the background of the emergence of Indian IT services MNCs and industry and the pattern of their HR practices. We then outline our research methodology and develop a framework based on our qualitative data findings, identifying key global HR roles and the factors that influence their development. We conclude by discussing the key outcomes of our study and their implications on future research agenda.

\section{HR Roles \& Influencing Factors}

With its focus on internal firm resources, such as intellectual capital, as sources of competitive advantage, the resource-based view (RBV) of the firm has been instrumental in the development of strategic HRM (SHRM) (Wright, Dunford \& Snell, 2001). However, RBV needs to be revitalized through continuous innovation on its inter-linkages with other perspectives, processes, micro-foundations and sustainability (Barney, Ketchen \& Wright, 2011) as well as with multi-level theoretical integration (Nyberg, Moliterno, Hale Jr \& Lepak 2012). Further, a firm’s ability to derive sustained competitive advantage from human capital depends "not only on the specificity of worker skills but also on the firm's ability to create and/or leverage both supply-side and demand-side mobility constraints to better retain human capital at discounts relative to rivals” (Campbell, Coff \& Krysynski, 2012, p. 389).

In the light of the above, researchers have identified several generic HR roles for the HR function. For example, Storey (1992) who examined the impact of workplace change on personnel practice in the UK proposed a fourfold typology of personnel roles - advisors, handmaidens, regulators and change-makers. Within the US context, Ulrich (1998) proposed that HR roles should be defined by their outcome and not by their activities and accordingly identified 'strategic business partner, administrative expert, employee champion and change agent’ as key HR roles. Further, Ulrich, Younger and Brockbank (2008) suggest that the HR structure should reflect the business organization and redefine HR roles and responsibilities to be 'dedicated HR, shared services and corporate functional HR' to suit the business structure of a holding company, allied/diversified organization and single/functional business, respectively. Analysing the 
contributions of Storey (1992) and Ulrich (1998), and based on his own research of HR managers of major UK based firms, Caldwell (2003) suggests that the role of the personnel professional over the years has altered in a number of significant respects, and has become more multifaceted and complex. He adds that neither Storey’s fourfold typology nor Ulrich’s initial model can adequately accommodate the emergent tensions between competing role demands, ever-increasing managerial expectations of performance and new challenges to professional expertise, all of which are likely to intensify in the future. To a great extent this is now valid in the present global context.

Following Simpson and Carroll (2008), we define role as an intermediary boundary object that incorporates the notion of identity. In the context of an MNC, the HR roles become global/international and accordingly acquire new dimensions and complexity. Some of these roles include champion of processes, guardian of culture, knowledge management champion (Budhwar, 2012; Sparrow et al., 2003), effective political influencer (Novicevic \& Harvey, 2001), network leadership and intelligence and managers of internal receptivity (Farndale et al., 2010a; 2010b). Similarly, Evans et al. (2011) identify three stages of international HRM (IHRM) and accordingly three roles for IHRM, namely, building HRM (the builder role), realigning HRM (the change agent role) and steering via HRM (the navigator role) to highlight the contribution that the HR function can make to value creation in MNCs.

According to Morris et al. (2009), MNCs struggle to transfer HR practices among their subsidiaries because of the complexity and context specific nature of these practices, and suggest that these challenges can be overcome by the managerial alignment of formal processes and systems, along with the informal alignment of people. Research evidence along these lines is now emerging (see Budhwar, 2012; Chung et al., 2012). The management of key human resources in an MNC depends on several contextual factors, such as the country of origin (Harzing \& Sorge, 2003), corporate strategy (Bartlett \& Ghoshal, 1989), IHRM strategy (Taylor et al., 1996), business structure (Ulrich, Younger and Brockbank, 2008), IHRM structure (Farndale et al., 2010b) and CEO perceptions (Chung et al., 2012; Brandl \& Pohler, 2010). Schuler, Dowling and De Ceri (1993) proposed an integrated contingency framework for evaluating strategic international HRM of MNCs (though not solely focusing on HR roles). In this regard they put together two sets of factors - exogenous (i.e., industry characteristics and country/region characteristics) and endogenous (i.e., structure of international operations, competitive strategy and experience in 
managing international operations). Figure- 1 summarizes the generic and global HR roles and the factors influencing their shape and strength. It highlights the rich diversity in global HR roles and influencing factors arising from the complexity of operating in an international environment.

(Insert Figure-1 about here)

From the above analysis it becomes clear that over the past decade or so some attention has been paid to explore the global role of HR in MNCs; however, there is scant research examining this in the context of MNCs from emerging markets and specifically from India. Keeping this in mind, we will revisit Figure-1 after presenting our findings to develop a framework for further research. We now proceed to provide a contextual background of the Indian IT services MNCs and HR practices therein.

\section{Emergence of Indian IT Services MNCs and Industry}

The aggregate revenues of the Indian information technology and business process outsourcing (IT-BPO) industry is estimated to be around US $\$ 100$ billion of which 70\% is derived from exports (NASSCOM, 2012). The triad regions of North America, Western Europe and Asia Pacific are the most important markets for IT services offshoring and accordingly, Indian IT companies derive two-thirds of their income from exporting to these markets (see Patel \& Budhwar, 2011). Apart from providing direct employment to 2.8 million people in India, the industry has presence in 52 countries with over 500 global delivery centers that employ over 600,000 foreign nationals (NASSCOM, 2012). The Indian IT services sector has also established its dominance as the world's largest destination for business process outsourcing (BPO) services delivery accounting for 34\% of the worldwide BPO market and the largest number of quality certifications for any single country (ibid).

The industry's competitiveness mainly stems from the quantity and quality of intellectual capital, world class process orientation and quality standards, and an innovative global services delivery model that leverages a mix of onshore, near-shore, offshore and global service offerings (e.g., Issac, Rajendran \& Anantharaman, 2004; Patel \& Budhwar, 2011). Chadee, Raman and Michailova (2011) found that human capital orientation in terms of recruiting, retaining and developing talent supported by the top management with a global mindset is one of the key success factors for Indian offshore service providers. Another study highlighted the importance of management capability in effectively leveraging the intangible 
resources, namely human, organizational and relational capital leading to the successful performance of these firms (Lahiri, Kedia \& Mukherjee, 2012).

\section{HRM in Indian IT Services MNCs and Industry}

While there is scant literature on the nature of HRM systems/roles in the overseas operations of the Indian IT MNCs there is information regarding how human resources are managed and the strategic role played by the HR function in their Indian operations. Pursuant to the liberalization of the Indian economy in early 1990s, the HR profession in India has become more global, particularly in industries such as IT, where intellectual capital is the key to sustainable competitive advantage (Budhwar \& Varma, 2011). Reflecting this view, Mathew and Jain (2008) found no difference between the HRM practices of domestic operations of Indian IT MNCs and foreign MNCs in the IT industry operating in India. According to Sanyal and Sett (2011), Indian software firms deploy HR options, i.e., investment in human capital, to address environmental uncertainties; for example, they adopt a "bundled" set of HR practices, such as competency frameworks in employee selection and continuous training to overcome obsolescence of technical skills; competitive pay, employee empowerment to address potential employee turnover and productivity; HR planning and staff deployment across projects, multi-skilling and team-based work to address variations in demand for manpower; and performance based pay to address fluctuations in employment costs (also see Budhwar, Varma, Malhotra \& Mukherjee, 2009). Other studies identify employee involvement, career development, comprehensive training, development oriented performance management, the use of HR metrics and an employee-friendly work environment as key facets of strategic human resource management (SHRM) in Indian IT companies (Mulla \& Premarajan, 2008; Paul \& Anatharaman, 2004).

In comparison to traditional Indian firms (e.g., manufacturing), Indian IT \& BPO firms are clearly adopting a formal, structured and rationalized approach to the management of their human resources (Budhwar, Luthar \& Bhatnagar, 2006; Budhwar et al., 2009). However, the global IT services industry is extremely dynamic and fast changing with “emerging verticals” such as healthcare, retail, defence and public sector; “emerging geographies”, such as the Asia Pacific, and “emerging technologies” like cloud computing are changing the IT services landscape (Wharton, 2011). 
In the backdrop of the above, the main research questions for our study are: "What are the strategic roles played by the corporate HR function in the internationalization and global operations of the Indian IT services MNCs; what are the key determinants of those roles and what challenges does HR face moving forward”?

\section{Research Methodology}

In order to address the above research questions, we selected four case study firms (called by their pseudonyms, Alpha, Beta, Gamma and Delta) from a population of Indian IT MNCs based on their success in international market penetration and their reputation for excellence in HRM practices, as demonstrated by external awards (see Table 1 for basic profile of the research firms and the spread of the sample). Considering the exploratory nature of our study, the qualitative case study method is an appropriate choice as it helps to examine in-depth organizational processes (Doz, 2011; Welch, Piekkari, Plakoyiannaki \& Paavilainen-Mantymaki, 2010). As Glaser and Strauss (1967) note, in case study research, sampling is chosen for theoretical not statistical reasons and "the goal of theoretical sampling is to choose cases which are likely to replicate or extend the emergent theory” (Eisenhardt, 1989, p. 537). We used 'convenience sampling' based on our personal and professional network as the participating firms needed to provide extensive access to their senior leaders across their global operations and the firms had to have subsidiaries in both the developed and developing markets. Eisenhardt (1989, p. 545) believes that four case studies can provide reasonable empirical grounding in case study research.

Given the exploratory nature of this research, we felt it sensible to speak to the subject matter experts and conducted in-depth interviews with 51 senior managers, including 32 line managers and 19 HR managers located at their Indian headquarters, as well as subsidiaries in the USA (as a representative developed market) and in China (as a representative developing market). Each interview typically lasted an hour and was recorded and transcribed. The positions of interviewees are mentioned next to their quotes in the findings.

(Insert Table-1 about here)

We used semi-structured interviews that covered a range of issues, such as the process of internationalization, differences in approach to control and coordination issues pertaining to HR in both 
developed and developing market subsidiaries, and the evolution, role and contribution of the HR function. As the data collection spanned over two years (2008-2010), it provided the opportunity for the researchers to overlap data analysis with the data collection, and gave them the freedom to make adjustments and refinements to the interview protocols to cover new developments in the industry. Thus, the flexibility to adjust the research instrument and data collection methods provided us with "controlled opportunism” (Eisenhardt, 1989, p. 539). We used multiple investigators with extensive experience in HRM in emerging markets as it added to the richness of the data and enhanced confidence in the findings. While two researchers collected the data, the third objectively scrutinized the evidence without being immersed in case details.

We used the "thematic analysis" approach, which we found to be particularly relevant and useful for our study as it goes beyond a single epistemic position to cover both realist and constructivist approaches (Braun \& Clarke, 2006). Raw interview transcript data were first open-coded using the NVivo program. The common statements were then identified and used as the basis for the initial set of coding categories, which were subsequently refined and modified based on inductive reasoning and the existing literature. This iterative process continued until theoretical saturation was reached. In the final stage of our data analysis we first looked at "within-case” data to "become intimately familiar with each case as a standalone entity" in order to derive unique patterns of each case. We then undertook a "cross-case” analysis by comparing and contrasting the key themes identified in each case in order to "look for within-group similarities coupled with intergroup differences” (Eisenhardt, 1989, p. 540). Thus, we were able to move from initial impressions to informed judgements of key themes in the raw interview data. This also assisted us to develop a broad conceptual framework of global HR roles and factors influencing their development for future research.

\section{Results}

Based on our data analysis, we identified five distinct roles and contributions from the HR function in the research firms. We describe each of these roles in terms of what they mean, how they are conceptualized at the corporate level and implemented by the subsidiaries, the factors influencing their development and finally the challenges faced by the HR function in performing these roles. 


\section{Strategic Business Partner}

A common theme across all four case studies is the acute awareness of the critical importance of HR to the business and HR's deep embeddedness within the business. Both the business and HR leaders stressed how critical intellectual capital and people management are to the survival and future of their global business. This is illustrated in the following interview quotes:

Yesterday was all about automation, industrialization, productivity through repeatability of manufacturing processes. Today is all about people ... intellectual property ... innovation (Chief Operations Officer [COO], Gamma).

When an industry is evolving all the time, people become important; so our primary focus is on people and that philosophy lends itself to the industry that we are in and that is where our success basically comes from (Chief Sales \& Operations Officer - Americas, Beta).

'Employees-first, customers-second', is our keyword. It is the employee who delivers results to a client; so, if you make the employee comfortable and committed, contribution will automatically follow, i.e., our business philosophy is to be employee-centric (Vice President [VP] - Business Development, Delta).

The strategic embeddedness of HR into the business is manifested in many ways, however two aspects stand out, first, the presence of business managers in HR roles, and second, organizing HR on business lines and running HR as a strategic business unit (SBU). At Alpha, the top five corporate HR leaders were recently moved from line responsibilities into HR. At Gamma, the HR function was headed by a member of the board of directors with other line responsibilities. At Beta, the global HR function was headed by the Chief Operations Officer in Americas - the company’s biggest market. Similarly, at Delta, business managers take an employee centric role by managing their own HR functions.

The organizational structure of HR in our case companies also mirrored the business structure. This was seen as helping HR to be close to the customer. Some examples of how this is conceptualized and implemented in the research firms is evident in the following interview quotes: 
Corporate HR at Gamma follows the global delivery model that the business units follow in terms of HR-IT systems, claims processing and HR help desk being located in a low cost destination ... There is also a clear separation between the strategic HR functions and administrative HR functions. For example, the core HR functions, such as compensation and organizational development are run as centers of excellence at the back-end. At the front-end, Business Partner HR (BPHR) functionaries are embedded in every business unit by being localized and act as the face of HR to employees on all matters of their employment. At the same time, BPHR units act as a voice of employee to back-end HR to take back employee feedback and influence change management (HR Head - Americas, Gamma).

As an organization, we are structured as Vertical Business Units (VBU), Horizontal Competency Units (HCU) and Regional Business Units (RBU). Both VBUs and RBUs are together called Customer Facing Units (CFU) as they drive the business in collaboration with HCUs. The whole structure revolves around the customer with one principal relationship manager handling each client. HR acts as a single HCU delivering complete (suite of) HR services to both VBUs and RBUs (HR Head, Alpha).

The global HR function is run not from India but from the USA. Thus, strategic direction in HR is shaped by both the corporate and subsidiaries in equal measure ... Just as we have processes for software development, HR has developed capability framework for each role (General Manager [GM] - Talent Engagement \& Development, USA, Beta).

As a result, HR seems to occupy a central place at the strategy table. Indeed, this is supported by the evidence where all the research firms have HR represented at the board level, have a written HR strategy, and have HR involved from the outset in the development of corporate strategy which allows HR to play a proactive role. Such an active involvement of HR is seen as assisting these firms to make sensible business decisions and improve organizational performance.

While corporate leaders maintain that subsidiaries are given enough autonomy, several business and HR leaders in subsidiaries feel that there is too much centralization at the corporate level in terms of decisionmaking and their voices are often not heard. For example, a Regional Head at Gamma’s US subsidiary, an 
American, believes that many of the Indian IT firms are far more centralized in decision making than their local counterparts which in his view results in the corporate function being "overwhelmed with so many things coming to it for review and approval ... (therefore), I don't think we've got the mix totally right." With regard to HR, he says: "The corporate HR kind of works in a vacuum ... (I wish) there had been more engagement and inclusiveness in the process ... instead it ends up being too India-centric.” Similarly, an American manager at Beta's US subsidiary says "all the decisions are perceived to be coming from India ... we need more local decision making and local executive presence, there is no doubt about it."

The HR leaders at subsidiaries also seem to concur with such feelings:

There is still lot of control from the headquarters ... (it is because) the employee numbers are so large in India ... we have made an effort both ways to educate the headquarters in terms of the needs of the local employees and at the same time educate the locals in terms of the need to confirm to the global (policy framework) (HR Head, Americas, Gamma).

Definitely a very significant or almost all control is from India. The guideline(s), the philosophy and the principles that govern any part of the world except for the compliance part are largely (based on how) people see in India ... this is an area which needs to be articulated and addressed (Assistant VP - HR, Americas, Alpha).

The above findings highlight an interesting dynamic, i.e., how the HR function in the research firms has been able to play the strategic business partner role, albeit without much active participation of HR from its subsidiaries. Nevertheless, as the Indian IT MNCs further grow and mature in their international operations, this issue is likely to be addressed.

\section{Guardian of Culture}

Both the business and HR leaders in all the case organizations maintain that it is the value system of the company that glues the organization together, and it is the core that remains constant and undiluted throughout their global network (perhaps the above highlighted centralized approach is helping in this). The core values espoused in the research firms uniformly stress the importance of integrity, fairness, 
transparency, acting with sensitivity, trust, flexibility, good corporate citizenship, individual dignity and professionalism. At Gamma, the value system is "time and context invariant", according to its COO. At Beta, the Joint CEO maintains that the company's value system is "non-negotiable" and according to the Senior VP of a vertical business unit, "the ability of Beta to drive that culture down the organization in spite of rapid growth has been a cause for success.”

HR is seen as playing a key role in embedding the core values across global operations through multiple means, such as education and role modelling (e.g. at Gamma), mandatory induction program on values, leaders talking about values in open forums (e.g. at Beta), aligning individual values to organizational values by explaining the "how of doing business" and by making the leadership team accountable to the workforce by "inverting the organizational pyramid” (e.g. at Delta), “nurturing talent”, achieving “cultural fit”, instilling “entrepreneurial instinct” through “distributed leadership and flat structure”, and being a “listening organization” (e.g. at Alpha).

We also found that the case study firms follow certain core HR policies and roll them out across their global network in order to maintain a strong organizational culture with some adjustment as in each geographical location, be it the recruitment policy at Gamma, the performance management at Beta, the compensation system at Alpha or the employee-first policy at Delta. To maintain uniformity of core policies across the global network, Gamma either sends an expatriate from headquarters to an overseas subsidiary to hire and train a local head, or hires a local head from the beginning and sends expatriates for support services, such as HR and finance, to establish or transfer their organizational value system and global policies. In terms of HR policies, the recruitment process (e.g. eligibility criteria and the policy not to headhunt) is the same globally with slight variations permitted in the way it is implemented (e.g. nature of selection tests).

At Beta, performance management is one of the core HR policies. Their GM - HR explains: “There's no variance in the performance oriented culture ... however, the implementation aspects depend on local practices and preferences. ” Underscoring the importance of policy flexibility needed in emerging markets, Beta’s Global Head of a vertical unit says: "You give extra time to your local people in emerging 
markets ... so that you're able to really listen to the inputs ... (because) there is a good deal that we don't know in the emerging market."

At Alpha, speaking about the emphasis on the global standardization of their compensation policies across the globe, their Head of Global Delivery \& Leadership Development said - “convergence (is most important) for compensation compared to any other HR policy.” However, the HR Head at Alpha's Chinese subsidiary raised several challenges in implementing their global HR policies.

China is traditionally very hierarchy oriented ... when the corporate office decided to make the (organizational) structure quite flat (by having) only five levels, we were really worried (that) it wouldn’t go really well in China ... if you look at the appraisal process, we identify the bottom ten percent and if we do not see an improvement ... we have to let them go. This is difficult to implement in China (due to) legal restrictions on employment termination. So you may have to balance looking at the regional realities.

Some HR managers in subsidiaries also highlight the implications of the demographic profile of the Indian workforce, which is relatively young (with an average age in the mid-20s). For example, the HR manager for Asia Pacific at Gamma says:

Most of the policies are centered around young employees who are flexible to move anywhere but work-life balance becomes a major issue as they get married and settle down (because) people are reluctant to move as freely as before ... to date most of these moves are managed on a case to case basis (but) there is no global mobility framework in managing talent.

Similarly, as pointed out by the HR manager at Gamma's US subsidiary:

As a company we expect 24/7 delivery model and (when) we find that not everyone is up to that it does create an issue ... it is not easy building a multicultural diverse organization ... age has a big impact on this ... (for example) average age of an American worker is 46/47 ... it is a challenge.

The above analysis highlights that all the research firms see their organizational values and culture as important and the HR function helps to transfer them to their overseas subsidiaries. A key issue then is 
how the Indian IT MNCs continue to sustain their transfer of values globally as their workforce demographics change and as they pursue operations in diverse context.

\section{Builder of Global Workforce and Capabilities}

We found that in all of the case organizations, the majority of the clients are based in the US and the UK, while the employee base is still overwhelmingly Indian. The VP - HR (International Operations) at Beta believes that having exploited the labour cost arbitrage until now, the next stage of evolution for the Indian IT MNCs is to become more customer centric and solution oriented through innovation. From an HR perspective he sees the need to diversify the talent pool, having global policies and culture and building global leadership capability.

All the interviewees stressed that as part of a "de-risking” strategy, the research firms are actively pursuing to reduce their dependence on Western markets by spreading their operations in the "rest of the world” and in so doing, they are also trying to localize the workforce. At Gamma, the geographic source of income is currently $65 \%$ from the USA, $25 \%$ from Europe and $10 \%$ from the rest of the world. The company wants to change it to 40/40/20 respectively. Ninety percent of the IT development work at Gamma is currently being carried out in India which is also changing with more development centers being set up in both advanced and developing markets. Thus, Gamma aims to be a global multinational in all its dimensions - investor, clients and geography. According to Gamma’s Head of Corporate Planning: "In terms of diversity, we've got a fairly good spread, but the depth is something that we are still working on." Similarly, Alpha has set a target that "at least 15\% of what (it) did hitherto offshore must happen outside of India”. The situation at Beta is much better.

As part of our global delivery model, up to $60-70 \%$ of the work can be done remotely. And remotely today happens to be in India because India has the most cost effective IT talent base anywhere in the world. Currently we have $20 \%$ of the people who are locals. And that proportion has gone from $2 \%$ to $20 \%$ over the last 5 to 6 years due to three things. One is we have consciously decided to localize as much as possible (because), aspirationally we don't want to be an Indian, but a global multinational. Secondly, we have been involved in mergers and acquisitions, which have brought local people into our fold. Third, as our (employer) brand image has gone up we have been 
able to attract better people to join our company. So it's an evolutionary process (GM - Talent Engagement \& Development, Beta).

A constant theme across our interviews was the recognition of the need to hire local talent. The reasons include the formal and informal expectations of local governments to show long-term commitment to the local community by hiring and training locals, work visa requirements, the expectations of global and local clients to service locally with local labor, the need to spread the talent base beyond India, particularly in locations where there is good talent available at low cost and to gain local market share. Examples of the statements supporting such sentiments are provided below.

Local leadership is very important in China ... while the India based offshoring model has worked very well for Indian firms in Western markets, it does not work in developing markets because they are not used to service offshoring ... they need localization in leadership, selling and delivery (GM Beta, China).

(In Japan) due to unemployment, the government is making it difficult to get people from India ... (in Australia) all the IT companies are given a quota (to get foreign workers into the country) and the government is becoming extremely stringent about it (HR Head - Asia Pacific, Delta).

The leaders in all four case companies stress the need for and the efforts under way to localize the workforce. However, they also point out some of the challenges in doing so. For example, following are some of the problems associated with developing the talent base in China.

Most engineers come from manufacturing, non-IT background ... they have no total end-to-end outsourcing experience ... tolerance for ambiguity is a big problem ... very hierarchy conscious ... quality of spoken English is quite poor (Assistant VP-HR, Asia Pacific, Gamma).

Leadership quality is the biggest challenge ... we get more of a follower material ... the employment at-will as a concept has not yet emerged ... China is getting expensive. ... So you have to go and expand in tier two and tier three cities (Country HR Head of Alpha, China).

When it comes to the IT talent, the industry itself is pretty new and unlike India, in China IT is not a chosen job ... their sphere is so limited because every move they make, they are making it in 
Chinese ... it is not that they don’t know, they are pretty plugged on in everything, but they are plugged on in Chinese (GM of Delta, China)

Similarly, the HR Manager for Asia Pacific region at Gamma confirms that there is a real dearth of local IT talent in Australia and Japan as locals do not covet IT careers as much as Indians. The HR Head at Alpha believes that typically, 50\% of recruitment in the Indian IT industry takes place at the entry level and it is difficult to follow a similar policy in the US due to a lack of numbers and reluctance to pursue a career in an IT offshoring services business.

While all the research firms possess a well-known employer brand in India (as they typically top the employer choice surveys), the challenge is to create a similar global brand. Gamma’s HR Head believes the process has not been easy and the company has learnt many lessons and there is still a long way to go. An American manager at Beta agrees: "India owes it to itself to do a better job of branding so that it is not seen as a very foreign culture because there are many similarities between India and the United States (which) people don't realize”.

The above analysis highlights the strong challenges emerging from the different contexts (e.g., China and the USA) for the Indian IT MNCs to continue to reduce the dependence of Indian workforce overseas and groom local talent to work in their overseas subsidiaries. The 'builder' role of HR in the Indian IT MNCs then becomes critical as they pursue this transition, but also maintain their workforce competencies and organizational values in their global operations.

\section{Champion of Processes}

The Indian IT MNCs are well known for their business processes and systems. According to Beta's Senior VP - Global Programs (who is an American national): “Indian multinationals are known to have very good processes, measure everything, put improvement plans in place and they are almost like clockwork”. The HR function exhibits similar commitment and enthusiasm to process orientation and metrics. This is clearly evident in the comment of Beta’s GM - Talent Management \& Engagement, USA, who says "Beta is a very process oriented company ... it is in our DNA, it is part of our culture". This is also confirmed by Head - Global Delivery \& Leadership Development at Alpha who says “... especially in the last three or four years the major focus is on converting everything into metric, that means our first 
language is the language of metrics ... one big exercise we are undertaking right now is to ensure that every (HR) process is validated globally.”

Process orientation helps these companies manage global scale and uniformity of core HR policies. For example as per the HR Head, Asia Pacific of Delta:

Because our employees keep moving, valuable data pertaining to the individual gets lost if you have multiple databases and applications, which are not parallel. So all of us are on the same goal matrix ... (for recruitment, performance management and compensation) ... all these systems run globally.

A manager at Gamma, which won an international award for the use of the Balanced Scorecard approach in performance management explains the logic behind such an emphasis:

The objective was to translate our strategy into a set of metrics and then flow those metrics down across the company ... and it translates into goal sheets for all the roles ... (this approach) has helped in many ways ... better sense of alignment, communicating to people as to what is important, reengineering the review process around metrics and better sense of focus (Head - Corporate Planning, Gamma).

Our case companies appear to make extensive use of human resource information system (HRIS) in their HR service delivery, particularly in providing administrative services using help desks, self-service portals, and shared services, which are run mostly from India. This is further reflected in the quote below.

We have invested significantly in upgrading HRIS to derive efficiencies in productivity, particularly in delivering HR administrative services. We will push more and more towards employee selfservice portals as our entire shared services are run from India. So it is about how we can structure ourselves for more efficient delivery to our employees to increase their satisfaction and at the same time how do we manage growth and cost (GM - Talent Management \& Engagement, Beta, USA).

The top Indian IT MNCs have grown at a breakneck speed in the last 10 years, virtually doubling in size (both in turnover and workforce) almost every two to four years. Many HR leaders acknowledge the challenge of sustaining such a high growth rate. One HR manager at Gamma compares it to "changing a 
flat tire while on the run" and believes HR has to cater to the business imperative for growth. The business head at Beta identifies three phases in his company’s evolution.

First 10 years we were pretty much an entrepreneurial company ... next 10 years was the excitement phase (with the) exhilaration of growth and success ... the current phase is more of the maturity phase ... saying how do we now consolidate our capabilities instead of just growing”.

Another business head at Gamma says:

We are running very hard as a company and therefore you could always blame it on time, saying I run out of time to think because I’m running so hard ... but then once you really step back and say am I really global, what do we do more now ... (we) still have some way to go, we're getting there.

In the present global economic downturn, another related challenge faced by Indian IT MNCs has been managing business slow down. As pointed out by a HR manager: “(with the onset of global financial crisis) to manage costs, we had to come up with creative solutions (such as) allowing employees to take a sabbatical for a year on $10 \%$ pay”.

While all the research firms wanted to reduce their reliance on Western markets, shifting to new markets has serious implications for both the business and HR. As indicated above, to work in diverse markets such as China needs different HR competencies as compared to developed nations, hence this has significant HR implications for the Indian IT MNCs. Also, during both challenging financial times and while moving into new markets, the role of HR further becomes critical to ensure the sustaining of core business processes which have enabled the Indian IT MNCs to become successful global players.

\section{Facilitator of Employee Development via Empowerment and Learning}

Our interviewees highlighted two particular aspects of employee development in their companies, first, employee empowerment and autonomy and second, career development through preference for internal candidates for promotion and continuous training opportunities for development. These aspects were clearly emphasized with statements, such as: 
We have a strong entrepreneurial culture ... we are able to give people the independence to do their best in the job (and it is supported by our) strategic business unit (SBU) driven structure (GM Talent Management \& Engagement, Beta).

In terms of compensation, there is very little difference between our competitors ... what makes the difference is the independence that you give to people in their day-to-day work (Head - Global Delivery \& Leadership Development, Alpha).

Our organizational culture is very open by being transparent to both internal and external customers and our leadership is built around independence (VP - Business Development, Delta).

Despite being part of the Indian high power distance culture, freedom to work in the Indian IT MNCs exists due to a mixture of reasons such as the nature of the sector where the diversity of clients and their requirements demand employees to be flexible and creative (though in a structured way). Also, the employees in this sector are generally young (new generation), qualified and highly skilled, hence the policy makers feel confident that they will be able to better handle empowering them, and it will act as a motivator and satisfier (see Budhwar et al., 2009).

The commitment to employee empowerment and autonomy are operationalized in a variety of ways. For example, Gamma has introduced “Voice of Youth” practice whereby the management council of each business unit has to have $15 \%$ of its people who are below 30 years of age. According to its Head of Corporate Planning: "What we are constantly reinforcing across the company is that hierarchy of ideas is more relevant than hierarchy of experience". Similarly, Beta has created an "Innovation Council" whereby anybody in the company can put up an idea for innovation and can be taken up for funding by Beta. Delta's “employee first philosophy translates into empowerment, trust, transparency, flexibility, focus on value not volume, and building long-term relationships” (Corporate VP).

The commitment to employee training in the research firms is demonstrated by the investment made in training infrastructure, the length and depth of technical induction training (typically six months for new campus hires) and the enthusiasm shown by top leaders and middle managers to become internal trainers. For example, Gamma claims to invest \$200 million per year for training and boasts arguably the world’s 
largest training facility. The training function in Beta is claimed to run "like a well oiled machine" with a proliferation of online courses, and tie-ups with world-renowned universities and 50 centers of excellence that track technology and market trends to constantly assess training needs. This is one of the reasons why people seem to prefer joining Indian IT firms. According to a Chinese project manager at Beta, they "offer very good training in comparison to other companies and it is not one-time (but) continuous training in different areas (which is) very important for me."

In terms of career development, our case study companies seem to show a distinct preference for internal candidates for promotions. For example, at Beta "the philosophy is that if there is an internal candidate who's even 70\% ready for a job we'd rather give him the shot as compared to going outside and getting a ready to use candidate" (Joint CEO). Similarly at Alpha, "internally we have a metric that $80 \%$ of the leadership requirements for (the) future should come from within ... even if the current employees are 80\% capable we would prefer to give them the opportunity and time to develop ... we say that the reward for a good job is (a) bigger job ... we also strongly believe that we need to do extraordinary things using ordinary people” (Head - Global Delivery \& Leadership Development).

The above initiatives are timely, as previously Indian IT-BPO firms were criticized for not having robust career development mechanisms in place that had resulted in serious discontent among employees, and was one of the major reasons for high attrition rates in the sector (see Budhwar et al., 2009). However, in the light of a spate of resignations recently at the top levels of major Indian IT firms, HR leaders acknowledge that succession planning is a major issue. One HR manager at Gamma noted that in most of the Indian IT firms "it has been the same management since they began ... no organization can survive this momentum with a tired management”. The GM - Talent Engagement and Development at Beta shares similar feelings: "(One of the HR challenges is) how do we build leadership cadre across all levels because today it is happening more by accident than by design". Reflecting on how most of the leaders are home-grown and not hired laterally, another HR manager says “ “... we tend to reject people who don't fit in to a certain way of working ... it is the same with our other Indian competitors ... we struggle to diversify our leadership base by hiring from outside". 
The major challenge for senior decision makers is to realize the need for a flexible approach to fill senior leadership assignments, which should be open to hiring host and third country nationals for key positions. This will hopefully help to tackle the succession problems experienced by Indian IT MNCs and will also get fresh thinking at the board level.

Most leaders, both in business and HR, recognize the need to learn to become global enterprises. They compare themselves to global IT majors such as IBM and Microsoft, and stress that as "infant" multinationals, the only way to secure their future is to constantly learn and innovate with the intention to develop a global mindset. The GM - Talent Engagement \& Development of Beta and COO of Gamma make useful comments in this regard as below:

Compared to IBM we are not there ... They know how to manage a global workforce ... (for example) the rigor of their processes, their learning systems, their ability to institutionalize certain things in a global way ... our training facilities in India are world class but we (have not yet) institutionalized that in every global location ... (so), we are still in the catch up phase.

Most of (the Indian IT multinationals) are first-generation multinationals and their internationalization truly started occurring in the last 15 years ... therefore, if you compare them with well established multinationals such as GE which is 150 years old, we have progressed much faster and deeper in the comparative time frame ... so, it is a maturity issue ... the only area where we have been lagging is the global employee base but that is changing very fast.

The HR function in the case firms has already played a key role in making them successful Indian IT MNCs, but it further has a major role to play in order to help these firms become leading global MNCs. Developing a global mindset in order to think and act as a global MNC is not easy. Indeed, these firms also need to have the ambition to learn the global ways of doing things in order to fulfil such aspirations. As neatly summed up by the Chief Sales \& Operations Officer - Americas at Beta "the challenges (we face) are not so cultural (but) more evolutionary issues, more globalization issues, more scalability issue(s) ... have I learnt fast enough, that is the bigger challenge." 


\section{Discussion}

It is now well established that the HR policies and practices in the Indian IT services industry are well developed and comparable to global best practices on formalization and rationalization (see Budhwar \& Varma, 2011). However, we still do not have reliable information regarding the roles the HR profession plays in this industry and the factors influencing their development and implementation. This research aimed to fill this gap. It also attempted to highlight the strategic HR challenges faced by the HR function of the Indian IT MNCs in the context of the fast changing global IT landscape, emergence of globalized services business delivery models and emerging industry segments and geographies. Figure 2 summarizes our conceptual framework outlining the global HR roles, influencing factors and challenges. The framework has been developed based on our qualitative interviews findings and is presented in a logical manner where linkages are drawn between key determinants of the five identified HR roles and the resultant challenges for the HR function in the research firms.

\section{(Insert Figure 2 about here)}

Our analysis identifies five key HR roles and the immense contributions the HR function has been making towards the global success of Indian IT services MNCs. First, the ‘strategic business partnership' of HR is manifested in several ways: starting with the acute awareness of the importance of people management in the strategic mindset and apex of the research organizations, the strong involvement of line managers in HR policy formulation and implementation and of HR managers in business strategy, and the design of HR organizations as a strategic business unit in order for it to become customer-centric. As emphasized by Ulrich, Younger and Brockbank (2008), "like any value-creating staff function, HR departments should operate as a business within a business” (p.829).

Such a structuring of the HR function helps to achieve the required fit, internal coherence and consistency with other functions/departments of the firm; which is known to contribute to improved organizational performance (see Evans et al., 2011). The increasing involvement of HR at the corporate level decisionmaking process in the case study companies is in line with previous academic research on strategic HR (see Brandl and Pohler, 2010). This is not surprising considering that the Indian IT MNCs are in many respects, ‘born-globals’ (Varma, 2011), as right from their inception they have focused on Western 
markets and have therefore, placed HR at the forefront of their business and international strategy. Being a 'people centric' industry with literate and skilled employees, it became clear to the employers at the infancy stage of the industry about the need to adopt a strategic partnership approach towards the management of their human resources (e.g., Nayar, 2010). However, now that they are focusing more on their entry into the emerging markets in line with the changing global economic landscape, it will be interesting to see whether and how their HR strategic partnership role will change. For example, our study has highlighted how the research firms are finding it challenging to roll out globally standardized HR policies in China. This is mainly due to a combination of reasons such as the lack of experience of Indian firms in China, and also the many differences between the Indian and Chinese business set-up.

Accordingly, there are variations in the key determinants of HRM practices and policies (e.g., institutional - like legislation and unions) in the two national contexts (see Björkman, Budhwar, Smale \& Sumelius, 2008). The strategic business partnership role of HR in the Chinese operations of the Indian IT service firms then becomes critical in ensuring appropriate adaptations/adoptions are carefully made to suit the business context in order to effectively utilize the available human capital and successfully transfer their core business values globally. This also forces the Indian IT service firms to further acknowledge the need to pursue a different approach to the management of their human resources while operating in a developed nation versus an emerging market context. It seems that the strategic business partnership HR role of Indian IT service MNCs is providing the needed vision and flexibility to make such country/situation specific adjustments.

The second role of 'guardian of culture' is about institutionalizing the core value system and key HR processes across the global network to build a strong organizational culture. The resource-based view (RBV) of the firm clearly identifies this role as one of the most difficult to imitate competitive advantages in leveraging intangible resources, capabilities and competencies (Wright et al., 2001). Building on the above discussed first HR role, the HR function in the Indian IT service MNCs further plays a crucial role in creating and maintaining a unique organizational culture via the full suite of HR activities including recruitment, induction, training, continuous professional development, aligning individual and organizational values, creating a performance oriented culture, being open to innovative ideas and rewarding employees for achieving challenging targets. As pointed out in related literature, the guardian 
of culture role is closely associated with 'knowledge management champion' and 'effective political influencer’ roles (see Sparrow et al., 2003; Novicevic \& Harvey, 2001).

Nevertheless, as Indian IT service MNCs become more global by entering into new geographies, the transfer of such organizational culture across diverse contexts (due to significant institutional and sociocultural differences - amongst others) is becoming a major challenge. This is further accentuated by the increasing demographic diversity of employees working in Indian IT services MNCs. A combination of factors such as certain industry specific characteristics (e.g., metrics based deliverables to global clients, adoption of human resource information systems and the people centric nature of the firms operating in the sector) and a serious effort made by the HR function (such as via recruitment and development) to preserve their organizational culture in their overseas operations (with minor amendments) is enabling all the research firms to successfully globally transfer their core business values.

The third crucial role played by HR in the success of Indian IT MNCs is that of the 'builder of global workforce and capabilities'. In order to achieve geographical diversification Indian IT MNCs are moving away from their dependence on traditional markets in the USA and Western Europe and into the fast growing Asia Pacific and Central and Eastern European regions. In order to do this effectively, they have to considerably reduce their reliance on the Indian workforce, develop global leadership and mindset, and seriously pursue localization of their global workforce. Even though this has started to happen in recent years, partly by design and partly by business and political necessity, there is still a long way to go.

Our findings suggest that there is still a strong centralization of decision making in the headquarters of Indian IT MNCs, and the reluctance of their corporate offices to shed their India-centric thinking in policy making and implementation. In such circumstances, the HR function of these firms faces several challenges in its quest to build a global workforce as IT is not a coveted career in most other emerging nations and the Indian IT MNC as an employer brand is still not strong globally. Perhaps the mergers and acquisitions and developments of strategic alliances with local firms route adopted by most Indian IT firms to internationalize is allowing them to acquire local talent in different national settings. In such cases, specialists from India tend to train the host country nationals to enhance their capabilities. The HR function plays a key role in both coordinating and transfer of such development. Also, many Indian IT 
MNCs send a large number of their India based employees overseas to deliver on specific projects at the facilities of their clients, such as the utility firms in the UK (see Patel \& Budhwar, 2011). This creates an opportunity for the host country nationals to work and learn from the Indian IT specialists resulting in the development of global capabilities.

The fourth HR role identified in this research is the 'champion of processes', metrics and the extensive use of human resource information systems. The HR literature reiterates the crucial role of technology in automating administrative functions so as to focus on strategic issues (Kavanagh, Thite \& Johnson, 2012) and the development of HR metrics to make HR more accountable and results-oriented (Beatty, Huselid \& Schneier, 2003). In this role, the HR function in the Indian IT services MNCs has been able to build its process capability just as its business counterparts have done in running their businesses. The HR function has played a significant role in keeping the processes efficient and integrated during the growth phase of the Indian IT service MNCs when they grew at an exponential rate. It has ensured the existence of the right competencies, encouraged and rewarded innovation and performance and the sustaining of growth. However, this role also indicates the extent of subsidiary dependence on headquarters, with its positive (uniform culture) and negative (centralization of decision making) consequences.

The fifth HR role we identify is that of 'employee development via empowerment and learning'. Cappelli et al. (2010) show how several Indian firms make "extraordinary investments in their employees and empower them in decision making”, take "long-term, internally focused view”, engage employees through transparency and accountability, and invest heavily in employee training. Employee engagement is crucial to spur innovation and creativity and we give several examples how the case study organizations try to achieve this by building a conducive organizational culture and work environment, providing continuous training and global career development opportunities. Such an emphasis of the HR function on employee development in the Indian IT service MNCs is instrumental in the creation of an intellectual capital, which is enabling these firms to achieve an exponential growth and competitive advantage, thus highlighting the relevance of the resource-based view of the firm to this analysis (see Wright et al., 2001).

While so far the Indian IT services industry has achieved remarkable success with HR playing a strategic role as described above, the way forward is full of challenges. The industry has grown too fast too quickly, 
particularly in the last decade, but the global economy is facing structural changes and painful readjustment. Our findings suggest that the top management in our case study firms is quite "tired" and has not paid enough attention to leadership succession planning, particularly in hiring people from outside. MNCs from emerging economies typically struggle from the liabilities of country of origin, foreignness, newness and smallness (Thite, Wilkinson \& Shah, 2012) and these liabilities somewhat restrict their ability to build a strong global employer brand. However, our case study firms seem to be acutely aware of these challenges and appear keen to learn and adapt.

While many of the global HR roles identified in our study are similar to those that are found in previous research studies in other contexts, it is important to note that the conceptualization and operationalization of these roles might be quite different in the context of emerging economy multinationals. For example, while the deployment of HR options and the bundling of HR practices in Indian software firms, as pointed by Sanyal and Sett (2011), mirror those in Western firms, there are implementation hurdles, including centralization of the decision making process and lack of global managerial talent pool due to ethnocentric attitude to managerial staffing. This may be due to cultural nuances of a collectivistic society as well as lack of global experience and exposure.

Based on the above analysis, our study has systematically developed a framework (see Figure 2) outlining the global HR roles, their influencing factors and challenges the HR function faces from the perspective of Indian IT service MNCs. It adds to the growing body of literature on HR roles in MNCs, especially those from emerging markets in a multi-polar world characterized by a complex and diverse set of global, national and organizational contexts and cultures. A novel contribution of our study is it's unearthing of the importance of corporate HR role as the 'builder of global workforce and capabilities'. This is a common issue for all MNCs but has been relatively underexplored in the HR role literature. We expect that as the emerging economy multinationals further expand their international operations and global workforce, this role will be a key determinant of their success in global talent management. The ‘facilitator of employee development' role supports Jackson’s (2002) view of differences in 'locus of human value' and provides further empirical evidence of humanistic view of people management by Indian firms in line with similar observations made by Cappelli et al. (2010). 
While proposing a typological approach to theory building on HR roles as above, following Doty and Glick’s (1994) advice, we would like to explicitly state our theoretical assertion that the bundling effect of these HR roles has lead to organizational effectiveness in our case study companies with the proviso that the nature, strength and configuration of these roles are likely to change depending on the factors affecting their development and the specific challenges faced by organizations in performing these roles as outlined in Figure 2.

\section{Implications and Conclusion}

Apart from adding to the growing but still underexplored literature on emerging markets' MNCs, within the HR domain, our study sheds some much needed light on the discrepancy between ideal versus practised HR roles as seen at different levels of management, namely corporate and subsidiary levels (de Guzman, Neelankavil \& Sengupta, 2011). The paper also highlights that the ethnocentric or India-centric approach to HRM adopted by Indian IT MNCs in their global operations needs adapting to a more polycentric approach in order to fully utilize the benefits available from the local contexts, including the global talent. This will help Indian IT firms to address their emerging problems related to adapting to the other emerging nations context (such as China), and acquisition of global leadership to deal with succession concerns. Indeed, in order to be effective in new contexts, Indian IT service MNCs need to develop both awareness and new competencies to enable them to work well with locals of other developing nations. As Indian IT MNCs grow in size and ambition, more delegation of decision making to the subsidiary level is likely to loom high on the agenda. Equally, continued investment in HR is likely to become an imperative.

Our study expands on previous research on corporate/global HR roles in MNCs in three ways: one, it extends the context to fast growing emerging market MNCs, two, it either lends support to many of the generic and global corporate HR roles identified in previous research studies, or/and adds new roles (e.g., builder of global workforce and capabilities), and three, it outlines the situational prerequisites for the effective formulation and implementation of these roles (building on the contingency perspective). The HR challenges that accompany each of these roles may be specific to the Indian IT industry and organizational context and future research studies will need to determine whether they extend to other 
emerging market MNCs as well. Taken together, our study presents a context-specific and holistic configuration framework of corporate HR roles in MNCs.

As suggested by Kostova et al. (2008), our empirical framework (as proposed in Figure 2) extends the theoretical lens of institutional theory by going beyond its implied institutional imperialism by highlighting the diversity in HR policy making and implementation in the context of emerging economy multinationals (Brewster, Wood \& Brookes, 2008). An important implication of our study on institutional theory, from the perspective of international business, is that while the Indian IT MNCs have largely been able to overcome ‘institutional voids’ (Khanna \& Palepu, 2005) in their home country, such as poor infrastructure, political instability and interventionist government policies, by focusing on mature Western markets since their inception, they will now have to confront and address these voids as they seek to expand their operations in other emerging markets based in regions such as Eastern Europe, South America and the Asia Pacific. In such contexts, the global HR function may need to expand its horizons to add corporate social responsibility (CSR) activities to improve the availability and quality of human resources (such as curriculum development, academic-industry partnerships and internships) as well as to improve their global employer brand. Anecdotal evidence suggests that this is already occurring as many Indian IT multinationals have taken such initiatives to improve the image, supply and quality of IT workforce, both at home and abroad (Gurjar, 2009).

Thus, our study lends support to the theory of 'new institutionalism' as articulated by Paauwe and Boselie (2003) who argue that to achieve organizational success, HRM should not only aim for vertical and horizontal fit but also environmental fit. Our research also enriches the resource-based view (RBV) by shedding light on the Indian IT MNCs’ ability to create and/or leverage both supply-side and demand-side mobility constraints on their global workforce (Campbell, Coff \& Kryscynski, 2012). Another contribution of our study to RBV is towards addressing the issue of where, when and how human resources may be useful in deriving strategic competitive advantage (Priem \& Butler, 2001) in the context of Indian IT MNCs.

Given the importance of socio-cultural and institutional differences as key determinants of HRM policies and practices (see Björkman et al., 2008), MNCs need to deal with choices such as whether to adopt a 
global standardized or localized approach to structure their HRM systems in different overseas subsidiaries (see Evans et al., 2011). In particular when the Indian IT service MNCs do not have much past experience of dealing with these dilemmas, the findings of our research have practical significance. For example, it helps to convey messages to practitioners regarding the crucial role HR plays in the internationalization of an MNC, how HR helps in the creation of core business processes and ensure efficient delivery of results, how sector relevant organizational culture and values are created and maintained, and support employee development with empowerment, learning and career development. As pointed out by Jackson (2002), Western managers who are used to an instrumental view of people as a means to an end, need to be aware of an alternate perspective provided by a humanistic view that sees people as having a value in themselves as prevalent in certain non-Western emerging economies, such as India.

We acknowledge the limitations of our research. These include the collection of information via interviews solely from senior managers in four cases and that too from one industry and from one country and subsidiaries from two countries. Nevertheless, within these limitations and given the growing significance of Indian IT service MNCs and the scarcity of reliable literature on the covered research topic, we believe our analysis makes a useful contribution to the areas of international HRM, emerging HR roles in Indian IT MNCs, emerging markets MNCs approach to strategic HRM and the challenges facing the HR function of Indian IT MNCs. We believe the five HR roles identified in our research should be examined across other sectors and could be utilized to develop a framework to further examine them with larger and diverse samples. While we only have a top down perspective we recommend future research should acquire information from other levels of employees as well, especially middle managers responsible for implementing policies. Further, considering that the multinationals from emerging economies are in a constant state of transition and evolution, and until they reach a critical mass, future research should consider how HR roles are influenced by the dynamics of this change. From a theoretical perspective, we acknowledge and caution that a static portrayal of role undermines its social enactment and different constructions by actors performing these roles and therefore, we need to pay careful attention to process, identity and change subject to individual, organizational and institutional influences (Pritchard, 2010). 
By broadening the macro context of strategic HRM beyond the developed markets (Marler, 2012), this paper has provided new, though exploratory, directions for future theoretical and empirical research on SHRM in general and global HR roles in particular. The limitations of our study need to be seen as opportunities to further test and improve the configurational framework proposed by us. As a starting point, the framework can be used to explore how HR can be strategically positioned from a resource-based perspective and what attendant roles that corporate/global HR can play to make this happen within an institutionally embedded context of MNCs from emerging economies.

\section{Acknowledgements}

This study was part of a research project funded by a grant from the SHRM Foundation, USA. However, the interpretations, conclusions and recommendations are those of the authors and do not necessarily represent the views of the SHRM Foundation. The authors thank the two reviewers, Helen De Cieri and the editor for their constructive comments on an earlier version of this paper.

\section{References}

Barney, J. B., Ketchen Jr, D. J., \& Wright, M. (2011). The future of resource-based theory: Revitalization or decline? Journal of Management, 37, 1299-1315.

Bartlett C. A., \& Ghoshal, S. (1989). Managing across borders: The transnational solution. Boston: Harvard Business School Press.

Beatty, R. W., Huselid, M. A., \& Schneier, C. E. (2003). New HR metrics: Scoring on the business scorecard. Organizational Dynamics, 32(2), 107-121.

Björkman, I., Budhwar, P., Smale, A., \& Sumelius, J. (2008). Human resource management in foreignowned subsidiaries: China versus India. International Journal of Human Resource Management, 19(5), 964-978.

Björkman, I., \& Lervik, J. E. (2007). Transferring HR practices within multinational corporations. Human Resource Management Journal, 17(4), 320-335.

Brandl, J., \& Pohler, D. (2010). The human resource department's role and conditions that affect its development: Explanations from Austrian CEOs. Human Resource Management, 49(6), 1025-1046.

Braun, V., \& Clark, V. (2006). Using thematic analysis in psychology. Qualitative Research in Psychology, 3, 77-101.

Brewster, C., Wood, G., \& Brookes, M. (2007). Similarity, isomorphism or duality? Recent survey evidence on the human resource management policies of multinational corporations. British Journal of Management, 19, 320-342.

Briscoe, D. R., Schuler, R. S., \& Tarique, I. (2011). International human resource management - policies and practices for multinational enterprises. London: Routledge.

Bruton, G. D., \& Lau, C. M. (2008). Asian management research: Status today and future outlook. Journal of Management Studies, 45(3), 636-659. 
Budhwar, P. (2012). Management of human resources in foreign firms operating in India: The role of HR in country-specific headquarters. International Journal of Human Resource Management, 23(12), 25142531.

Budhwar, P., \& Varma, A. (2011). Emerging HR management trends in India and the way forward. Organizational Dynamics, 40, 317-325.

Budhwar, P., \& Varma, A. (2010). Guest Editors' introduction: Emerging patterns of HRM in the new Indian economic environment. Human Resource Management, 49(3), 343-351.

Budhwar, P., \& Debrah, Y. (2009). Future research on human resource management systems in Asia. Asia Pacific Journal of Management, 26, 197-218.

Budhwar, P., Varma, A., Malhotra, N., \& Mukherjee, A. (2009). Insights into the Indian call centre industry: Can internal marketing help tackle high employee turnover? Journal of Services Marketing, 23(5), 351-362.

Budhwar, P., Luthar, H., \& Bhatnagar, J. (2006). The dynamics of HRM systems in Indian BPO firms. Journal of Labor Research, 27(3), 339-360.

Caldwell, R. (2003). The changing roles of personnel managers: Old ambiguities, new uncertainties. Journal of Management Studies, 40(4), 983-1004.

Campbell, B. A., Coff, R., \& Kryscynski, D. (2012). Rethinking sustained competitive advantage from human capital. Academy of Management Review, 37(3), 376-395.

Cappelli, P., Singh, H., Singh, J., \& Useem, M. (2010). The India way: Lessons for the US. Academy of Management Perspectives, May: 6-24.

Chadee, D., Raman, R., \& Michailova, S. (2011). Sources of competitiveness of offshore IT service providers in India: Towards a conceptual framework. Competition and Change, 15(3), 196-220.

Chang, Y. Y., Mellahi, K., \& Wilkinson, A. (2009). Control of subsidiaries of MNCs from emerging economies: The case of Taiwanese MNCs in the UK. The International Journal of Human Resource Management, 20(1), 75-95.

Chung, C., Bozkurt, O. \& Sparrow, P. R. (2012). Managing the duality of IHRM: Unravelling the strategy and perceptions of key actors in South Korean MNCs. International Journal of Human Resource Management, 23(11), 2333-2353.

de Guzman, G., Neelankavil, J. P., \& Sengupta, K. (2011). Human resource roles: Ideal versus practices: A cross-country comparison among organizations in Asia. The International Journal of Human Resource Management, 22(13), 2665-2682.

Doty, D. H. \& Glick, W. H. (1994). Typologies as a unique form of theory building: Toward improved understanding and modeling. Academy of Management Review, 19(2), 230-251.

Doz, Y. (2011). Qualitative research for international business. Journal of International Business Studies, 42, 582-590.

Economist (2008). Emerging-market multinationals: The challengers. 10 January.

Eisenhardt, K. M. (1989). Building theories from case study research. Academy of Management Review, 14(4), 532-550.

Evans, P., Pucik, V., \& Björkman, I., (2011). The global challenge: International human resource management, New York: McGraw Hill.

Farndale, E., Scullion, H., \& Sparrow, P. (2010a). The role of the corporate HR function in global talent management. Journal of World Business, 45, 161-168.

Farndale, E., Paauwe, J., Morris, S., Stahl, G., Stiles, P., Trevor, J. \& Wright, P. (2010b). Context-bound configurations of corporate HR functions in multinational corporations. Human Resource Management, 49(1), 45-66. 
Ghemawat, P. \& Hout, T. (2008). The global giants: Not the usual suspects. Harvard Business Review, 86(11), 80-88.

Glaser, B. G., \& Strauss, A. L. (1967). The discovery of grounded theory: Strategies for qualitative research. New York: Aldine De Gruyter.

GMAC (2010). Global relocation trends. 2010 survey report. Woodridge, IL: GMAC Global Relocation Services.

Gurjar, N. (2009). A practitioner's perspective on the Indian info-services industry. In M. Thite \& Russell, R. (Eds.), The next available operator: Managing human resources in Indian business process outsourcing industry (pp. 115-144), New Delhi: Sage.

Harzing, A.-W., \& Sorge, A. (2003). The relative impact of country of origin and universal contingencies on internationalization strategies and corporate control in multinational enterprises: Worldwide and European perspectives. Organization Studies, 24(2), 187-214.

Issac, G., Rajendran, C., \& Anantharaman, R. N. (2004). Significance of quality certification: The case of the software industry in India. The Quality Management Journal, 11(1), 8-32.

Jackson, T. (2002). The management people across cultures: Valuing people differently. Human Resource Management, 41(4), 455-475.

Kavanagh, M. J., Thite, M., \& Johnson, R. (2012). Human resource information systems: Basics, applications \& directions ( $2^{\text {nd }}$ ed.). Thousand Oaks, CA: Sage.

Khanna, T. \& Palepu, K.G. (2005). Spotting institutional voids in emerging markets. MA: Harvard Business School Publishing.

Khavul, S., Benson, G. S., \& Dutta, D. K. (2010). Is internationalization associated with investments in HRM? A study of entrepreneurial firms in emerging markets. Human Resource Management, 49(4), 693711.

Kostova, T., \& Dacin, M. T. (2009). Theorizing on MNCs: A promise for institutional theory. Academy of Management Review, 34(1), 171-173.

Kostova, T., Roth, K., \& Dacin, M. T. (2008). Note: Institutional theory in the study of multinational corporations: A critique and new directions, Academy of Management Review, 33(4), 994-1006.

Lahiri, S., Kedia, B. L., \& Mukherjee, D. (2012). The impact of management capability on the resourceperformance linkage: Examining Indian outsourcing providers. Journal of World Business, 47, 145-155.

Marler, J. H. (2012). Strategic human resource management in context: A historical and global perspective. Academy of Management Perspectives. 26(2), 6-11.

Mathew, M., \& Jain, H. C. (2008). International human resource management in the Indian information technology sector: A comparison of Indian MNCs and affiliates of foreign MNCs in India. Advances in International Management, 21, 267-297.

McDonnell, A., Lamare, R., Gunnigle, P., \& Lavelle, J. (2010). Developing tomorrow's leaders-evidence of global talent management in multinational enterprises. Journal of World Business, 45, 150-160.

Morris, S. S., Wright, P. M., Trevour, J., Stiles, P., Stahl, G. K., Snell, S., Paauwe, J., \& Farndale, E. (2009). Global challenges to replicating HR: The role of people, processes, and systems. Human Resource Management, 48(6), 973-995.

Mulla, Z. R., \& Premarajan, R. K. (2008). Strategic human resource management in Indian IT companies: Development and validation of a scale. The Journal of Business Perspective, 12(2), 35-46.

NASSCOM. (2012). Indian IT-BPO industry. Retrieved from http://www.nasscom.org/indian-itbpoindustry.

Nayar, V. (2010). Employees first, customers second: Turning conventional management upside down. Cambridge: Harvard Business Press. 
Novicevic, M. M. \& Harvey, M. (2001). The changing role of the corporate HR function in global organizations of the twenty-first century. International Journal of Human Resource Management, 12(8), 1251-1268.

Nyberg, A., Moliterno, T. P., Hale Jr, D., \& Lepak, D. (2012). Resource-based perspectives on unit-level human capital: A review and integration. Journal of Management, OnlineFirst Version of Record, Sep 7, 2012, 1-31.

Paauwe, J. \& Boselie, P. (2003). Challenging 'strategic HRM' and the relevance of the institutional setting. Human Resource Management Journal, 13(3), 56-70.

Patel, C., \& Budhwar, P. (2011). Outsourcing and offshoring to India. In P. Budhwar and A. Varma (Eds.), Doing business in India (pp. 201-223). London: Routledge.

Paul, A. K., \& Anantharaman, R. N. (2004). Influence of HRM practices on organizational commitment: A study among software professionals in India. Human Resource Development Quarterly, 15(1), 77-88.

Priem, R. L. \& Butler, J. E. (2001). Is the resource-based "view” a useful perspective for strategic management research? Academy of Management Review, 26(1), 22-40.

Pritchard, K. (2010). Becoming an HR strategic partner: tales of transition. Human Resource Management Journal, 20(2), 175-188.

Ramamurti, R. (2004). Developing countries and MNEs: Extending and enriching the research agenda. Journal of International Business Studies, 35, 277-283.

Ready, D. A., Hill, L. A., \& Conger, J. A. (2008). Winning the race for talent in emerging markets. Harvard Business Review, November, 1-10.

Reilly, P. and Williams, T. (2012). The challenges to global HR: One way to go? People Management, September, 28-31.

Rosenzweig, P., \& Nohria, N. (1994). Influences of human resource management practices in multinational firms. Journal of International Business Studies, 20(2), 229-252.

Ryan, J., \& Gibbons, P. (2011). Reconciling pressures for integration and autonomy within multinational corporations: An examination of personnel policies and practices. European Journal of International Management, 5(6), 559-573.

Sanyal, S., \& Sett, P. K. (2011). Managing human resources in dynamic environments to create value: Role of HR options. The International Journal of Human Resource Management, 22(9), 1918-1941.

Schuler, R.S., Sparrow, P., \& Budhwar, P. (2009). Major works in international human resource management. In P. Budhwar, R. Schuler \& P. Sparrow (Eds.), Major works in international human resource management - volume 1 (pp. xxiii - xxviii.). London: Sage.

Schuler, R.S., Dowling, P. \& De Ceri, H. (1993). An integrative framework of strategic international human resource management. International Journal of Human Resource Management, 4, 717-764.

Scullion, H. \& Starkey, K. (2000). In search of the changing role of the corporate human resource function in the international firm. International Journal of Human Resource Management, 11(6), 1061-1081.

Sethi, D. (2009). Are multinational enterprises from the emerging economies global or regional? European Management Journal, 27(5), 356-364.

Simpson, B. \& Carroll, B. (2008). Re-viewing 'role' in processes of identity construction. Organization, 15(1), 29-50.

Sparrow, P., Harris, H., \& Brewster, C. (2003). Towards a new model of globalizing HRM. Paper presented at the 7th Conference on International Human Resource Management, University of Limerick, Ireland.

Storey, J. (1992). Developments in the management of human resources. Oxford: Blackwell Publishing.

Taylor, S., Beechler, S. \& Napier, N. (1996). Towards an integrative model of strategic international human resource management. Academy of Management Review, 21(4), 959-85. 
Thite, M., Wilkinson, A., \& Shah, D. (2012). Internationalization \& HRM strategies across subsidiaries in multinational corporations from emerging economies - A conceptual framework. Journal of World Business, 47(2), 251-258.

Truss, C., Mankin, D., \& Kelliher, C. (2012). Strategic human resource management. Oxford: Oxford University Press.

Ulrich, D. 1998. A new mandate for human resources. Harvard Business Review, 76(1), 124-34.

Ulrich, D., Younger, J., \& Brockbank, W. (2008). The twenty-first-century HR organization. Human Resource Management, 47(4), 829-850.

Upadhya, C. (2009). Controlling offshore knowledge workers: Power and agency in India's software outsourcing industry. New Technology, Work and Employment, 24(1), 2-18.

Varma, S. (2011). Born global acquirers from Indian IT: an exploratory case study. International Journal of Emerging Markets, 6(4), 351-368.

Welch, C., Piekkari, R., Plakoyiannaki, E., \& Paavilainen-Mantymaki, E. (2010). Theorizing from case studies: Towards a pluralist future for international business research. Journal of International Business Studies, 42, 740-762.

Wharton (2011). Indian IT services: Shaping up for the next big push. IndiaKnowledge@Wharton.

Retrieved from http://knowledge.wharton.upenn.edu/india/article.cfm?articleid=4573.

Wright, P. M., Dunford, B. B., \& Snell, S. A. (2001). Human resources and the resource based view of the firm. Journal of Management, 27, 701-721.

Yaprak, A. \& Karademir, B. (2010). The internationalization of emerging market business groups: An integrated literature review. International Marketing Review, 27(2), 245-256. 
Table 1: Organizational Profile and Sample

\begin{tabular}{|c|c|c|c|c|c|c|c|c|}
\hline & \multicolumn{2}{|c|}{ Gamma } & \multicolumn{2}{|l|}{ Beta } & \multicolumn{2}{|l|}{ Alpha } & \multicolumn{2}{|l|}{ Delta } \\
\hline $\begin{array}{l}\text { Year of } \\
\text { Establishment }\end{array}$ & \multicolumn{2}{|l|}{1981} & \multicolumn{2}{|c|}{$\begin{array}{l}\text { Entered IT } \\
\text { services business } \\
\text { in early 1990s }\end{array}$} & \multicolumn{2}{|l|}{1987} & \multicolumn{2}{|l|}{1976} \\
\hline Turnover (US\$) & \multicolumn{2}{|c|}{$\$ 6.80$ billion } & \multicolumn{2}{|c|}{$\$ 6.98$ billion } & \multicolumn{2}{|c|}{$\$ 1.13$ billion } & \multicolumn{2}{|c|}{$\$ 6.2$ billion } \\
\hline Employees & \multicolumn{2}{|c|}{145,000} & \multicolumn{2}{|c|}{120,000} & \multicolumn{2}{|c|}{40,000} & \multicolumn{2}{|c|}{90,000} \\
\hline Global Spread & \multicolumn{2}{|c|}{$\begin{array}{l}68 \text { development } \\
\text { centers including } \\
\text { US, China, } \\
\text { Australia, Japan, } \\
\text { Middle East, UK, } \\
\text { Germany, France, } \\
\text { Switzerland, } \\
\text { Netherlands, } \\
\text { Poland, Canada }\end{array}$} & \multicolumn{2}{|c|}{$\begin{array}{l}72 \text { global delivery } \\
\text { centers in over } 50 \\
\text { countries across } 5 \\
\text { continents }\end{array}$} & \multicolumn{2}{|c|}{$\begin{array}{l}\text { Development and } \\
\text { delivery centers in } \\
\text { US, Canada, } \\
\text { Brazil, UK, } \\
\text { Hungary, Egypt, } \\
\text { UAE, China, } \\
\text { Malaysia, } \\
\text { Singapore and } \\
\text { Australia }\end{array}$} & \multicolumn{2}{|c|}{$\begin{array}{l}\text { Operates across } \\
31 \text { countries } \\
\text { including USA, } \\
\text { UK, Finland, } \\
\text { Poland, Puerto } \\
\text { Rico, Brazil, } \\
\text { China, Malaysia } \\
\text { and Singapore }\end{array}$} \\
\hline $\begin{array}{l}\text { Select List of } \\
\text { Key HR Awards }\end{array}$ & \multicolumn{2}{|c|}{$\begin{array}{l}\text { •PCMM Level } 5 \\
\text { certification\# } \\
\text { •Most preferred } \\
\text { company to } \\
\text { work for in India } \\
\text {-ASTD Award } \\
\text { for Excellence in } \\
\text { Inclusivity } \\
\text { •Balanced } \\
\text { Scorecard Hall } \\
\text { of Fame Award }\end{array}$} & \multicolumn{2}{|c|}{$\begin{array}{l}\text {-PCMM Level } 5 \\
\text { certification\# } \\
\text {-ASTD Award } \\
\text { for training \& } \\
\text { development } \\
\text {-Among the top } 3 \\
\text { BPO Employers }\end{array}$} & \multicolumn{2}{|c|}{$\begin{array}{l}\text { •Ranks among } \\
\text { the top best } \\
\text { employers in } \\
\text { India } \\
\text {-ASTD Award } \\
\text { for learning }\end{array}$} & \multicolumn{2}{|c|}{$\begin{array}{l}\text { - Ranks among } \\
\text { the top best } \\
\text { employers in } \\
\text { India } \\
\text { • HR Leadership } \\
\text { Award }\end{array}$} \\
\hline Sample & Line & HR & Line & HR & Line & HR & Line & HR \\
\hline Headquarters & 2 & 1 & 3 & 2 & $1 *$ & 5 & 3 & 2 \\
\hline USA & 1 & 1 & 5 & 3 & 4 & 1 & - & $1 * *$ \\
\hline China & 3 & 1 & 4 & 1 & 4 & 1 & 3 & $-* *$ \\
\hline Total & 6 & 3 & 12 & 6 & 8 & 7 & 6 & 3 \\
\hline
\end{tabular}

\#People Capability Maturity Model (PCMM) is a framework developed by Carnegie Mellon University focusing on continuously improving the management and development of the human assets of an organization. Level 5 is the highest level.

*Five line managers were recently transferred to handle key HR portfolios and were counted under HR.

**The HR Head - Asia Pacific is based in Australia and handles both developed and developing markets in the region. 


\section{Figure 1: HR Roles}

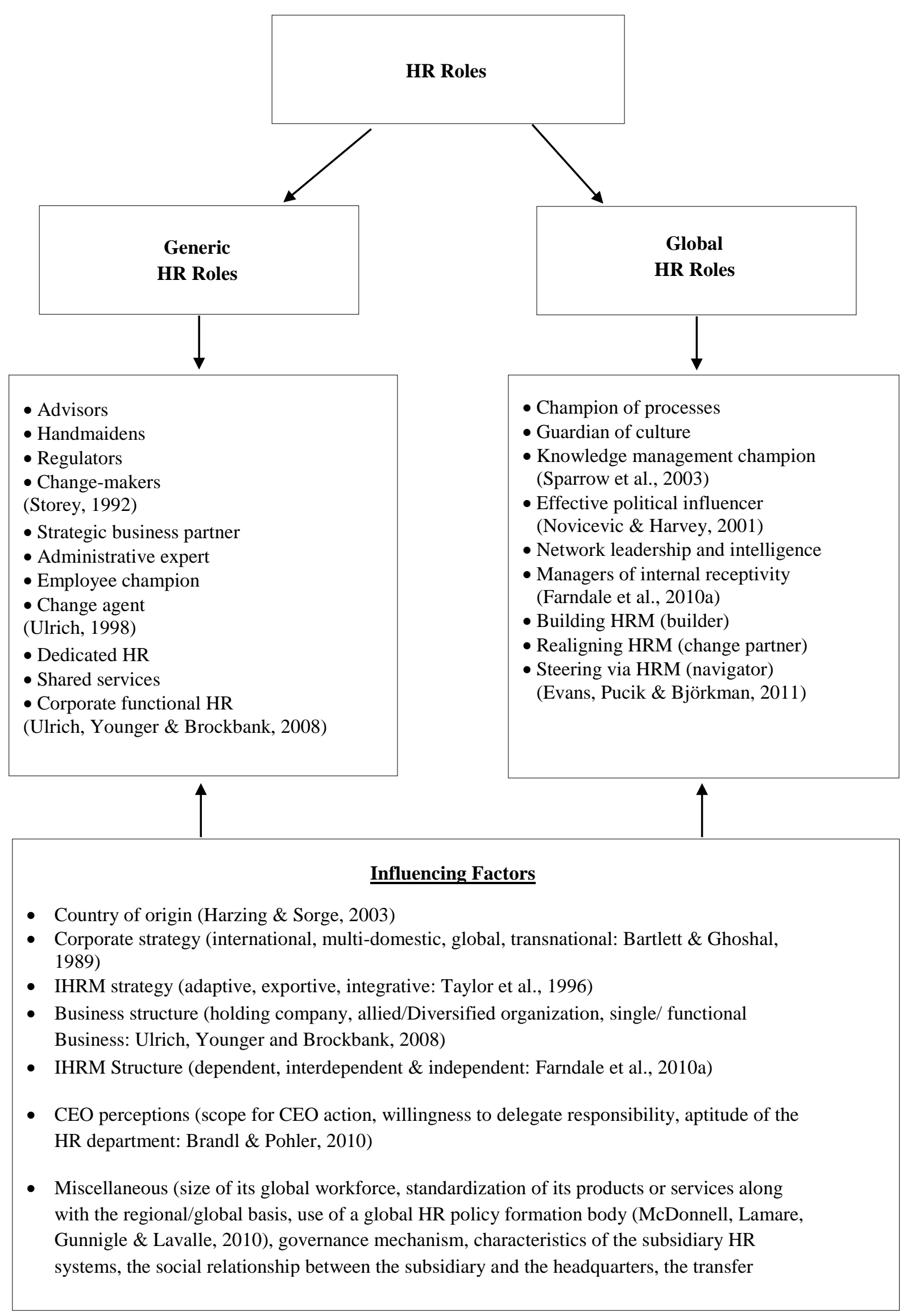


Figure 2: Framework on HR Roles \& Corresponding Influencing Factors \& Challenges in Indian IT Multinationals

Influencing Factors
HR Roles

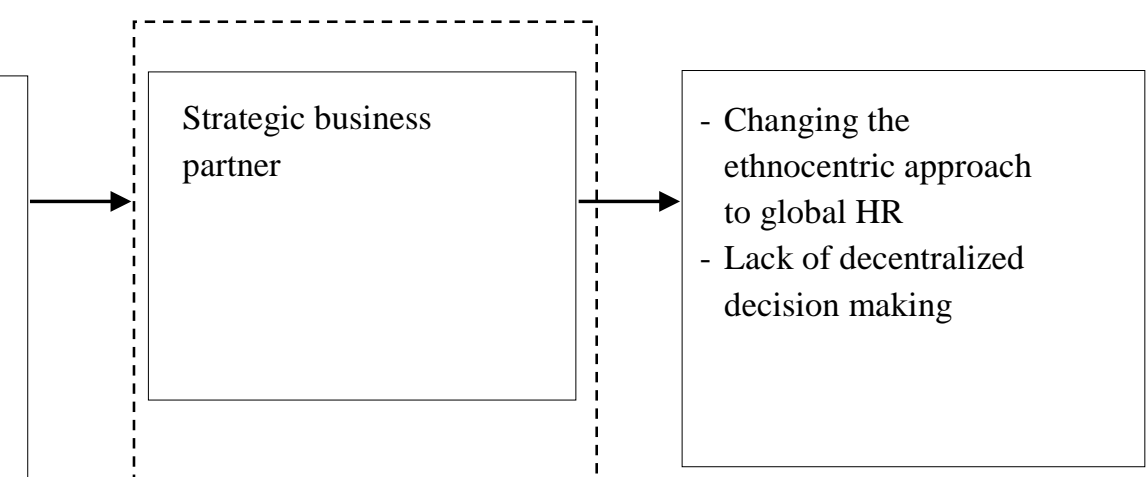

- Importance of organizational culture as espoused \& lived by leaders

- HR's strategic role in embedding core values in HR policies \& practices

- HR's ability to balance standardization \& customization of HR policy framework

HR Challenges

Changing the

ethnocentric approach

to global HR

Lack of decentralized

decision making

- Lack of global mindset

- Challenge of sustaining high growth rate

culture

- Lack of regional flexibility

- Challenge of managing
- Dependence on home country workforce \& expatriates for cost advantage

- Market pressure to diversify geographical client base as de-risking strategy

- Need \& desire to localize workforce \& leadership

- Strength of employer brand across the global network

- Breadth \& depth of process orientation to business

- Speed of internationalization

- Importance of metrics in performance management

- Adoption of human resource information systems (HRIS)

- Need for innovation \& creativity

- Strategic practices to embed autonomy at all levels

- Emphasis on \& investment in training

- Promotions from within diverse global workforce

Builder of global workforce \& capabilities

- Structural \& organizational constraints on localization of workforce in key markets

- Lack of succession planning in top management ranks

- Inability to attract \&

Champion of processes

Managing scale \& business cycles

- Ensuring, sustaining quality \& adapting to new markets

Facilitator of employee empowerment via learning \& development
- Inability/reluctance to develop a global leadership pipeline \& drawbacks of inbreeding

- Lack of global mindset

- Liabilities of newness \& smallness as firstgeneration multinationals 